Original paper UDC 1:001.53(045)

doi: $10.21464 / \mathrm{sp} 31203$

Received January $11^{\text {th }}, 2016$

\title{
Bo Mou
}

Department of Philosophy, San José State University, San José, California 95192-0096, USA

bo.mou@sjsu.edu

\section{How Constructive Engagement in Doing Philosophy Comparatively Is Possible}

\begin{abstract}
In this article I intend, on the basis of some previous relevant works on the issue, to further examine a range of conditions for maintaining adequate methodological guiding principles concerning how to look at the relation between distinct methodological perspectives in comparative-engagement exploration in philosophy. The purpose of this paper is to explore how, in the global context, distinct approaches in philosophy can be engaged in order to constructively talk to each other and make a joint contribution to the development of philosophy and society.
\end{abstract}

\section{Keywords}

constructive engagement, comparative philosophy, methodological guiding principles (and their adequacy conditions), methodological perspectives

In this article, on the basis of some previous relevant work of this author on the issue, ${ }^{1}$ I intend to further examine a set of conditions for maintaining adequate methodological guiding principles ('adequacy conditions') concerning how to look at the relation between distinct methodological perspectives in comparative-engagement exploration in philosophy. The purpose of this writing is to contribute to the exploration of how, in the global context, distinct approaches in philosophy can engage but constructively talk to each other and make a joint contribution to the development of philosophy and of society. My strategy is the following: First, as preliminaries, I briefly characterize

1

See Bo Mou, "An Analysis of the Structure of Philosophical Methodology: In View of Comparative Philosophy", in: Bo Mou (ed.), Two Roads to Wisdom? Chinese and Analytic Philosophical Traditions, Open Court, Chicago 2001, pp. 337-364; Bo Mou, "On Constructive-Engagement Strategy of Comparative Philosophy", Comparative Philosophy 1:1 (2010), pp. 1-32, http://www.comparativephilosophy.org; Bo Mou, "Constructive Engagement of Analytic and Continental Approaches Beyond the Western Tradition" [Introduction to Part Two], in: Bo Mou, Richard Tieszen (eds.), Constructive Engagement of Analytic and Continental Approaches in Philosophy: From the Vantage Point of
Comparative Philosophy, Brill, Leiden 2013, pp. 147-162, doi: https://doi.org/10.1163/9 789004248861; Bo Mou, "On ConstructiveEngagement Strategy in Studies of Chinese Philosophy", in: Sor-hoon Tan (ed.), The Bloomsbury Research Handbook of Chinese Philosophy Methodologies, Bloomsbury Academic, London - New York 2016, pp. 199-226, doi: https://doi.org/10.5040/97814 74295024.ch-010. This article is not to just repeat or reformulate what has been written before but contains some new contents, i.e., two more adequacy conditions, which have yet to be presented and explained in my previous writings in print. 
what the constructive-engagement strategy in doing philosophy is and introduce some preliminary conceptual and explanatory resources and relevant distinctions needed. Second, I further examine a range of ten related adequacy conditions in order to establish how distinct approaches in philosophy can constructively talk to each other and make a joint contribution to the development of philosophy and of society.

\section{Preliminaries}

In this section, as preliminaries, I first highlight the characteristic features and methodological emphases of the constructive-engagement strategy in philosophical exploration, and then I introduce some explanatory resources and conceptual distinctions needed in order to explore a range of adequacy conditions for the methodological guiding principles in doing philosophy comparatively.

\section{1 .}

The constructive-engagement strategy as one general strategic methodology in doing philosophy comparatively, generally but briefly speaking, can be presented in the following summarized way: It is to inquire into how, by way of reflective criticism (including self-criticism) and argumentation, distinct approaches from different philosophical traditions (whether distinguished culturally or by styles and orientations) can learn from each other and jointly contribute to the contemporary development of philosophy on a range of philosophical issues or topics, which can be jointly concerned and approached through appropriate philosophical interpretation and from a broader philosophical vantage point. The constructive-engagement strategy in doing philosophy comparatively can be effectively implemented in studies of any culture-associated philosophical traditions (such as the Chinese philosophical tradition and the Indian philosophical tradition) or orientation/style-associated philosophical traditions (such as the analytic tradition and the "Continental" tradition, both understood broadly). For example, specifically speaking, the constructive-engagement strategy in studies of Chinese philosophy is to implement the foregoing general constructive-engagement strategy in doing philosophy with focus on the constructive engagement of distinct approaches within the Chinese philosophical tradition, as well as from the Chinese tradition and other culture-associated philosophical traditions (including the Western and other non-Western traditions, though comparative Chinese-Western philosophy is often talked about or focused on due to its representative way in method, as well as in its substantial scholarship).

One can see from the foregoing brief characterization that the constructiveengagement strategy has five related methodological emphases (as highlighted in italics) in a coordinate way: (1) it emphasizes critical engagement; (2) it emphasizes the constructive contribution of each of the parties in critical engagement through learning from each other and a joint contribution to jointly-concerned issues; (3) it emphasizes philosophical interpretation of the addressed thinkers' texts instead of mere historical description; (4) it emphasizes the philosophical-issue-engagement orientation aiming at contribution to the contemporary development of philosophy on a range of philosophical issues that can be jointly concerned and approached through philosophical 
interpretation; and (5) it, thus, has the character of comparative philosophy as understood in one fundamental engaging way of doing philosophy.

One central concern in the constructive-engagement strategy is how to adequately look at the relationship between distinct approaches from different philosophical traditions (identities of philosophical traditions understood broadly, either culturally distinguished or orientation/style-identity-distinguished); this central concern constitutes the core part of the significant philosophical issue of how the constructive engagement in doing philosophy comparatively is possible. To explore the core part of this issue, we are concerned with the adequacy conditions for maintaining adequate methodological guiding principles regarding how to effectively look at the relationship between distinct methodological rationales underlying distinct substantial approaches in philosophy, i.e., distinct methodological approaches. For this purpose, the very notion of methodological approach needs to be refined in terms of a range of relevant conceptual and explanatory resources and distinctions.

\section{2.}

To have refined understanding and due resources, certain conceptual and explanatory resources and lexical distinctions are needed. As the details of these resources have been elaborated previously, ${ }^{2}$ my introduction to them here is brief.

The term 'method' or 'methodological approach' means a variety of ways that respond to how to approach an object of study. There are three distinct but related ways in which one can approach an object of study, which together constitute three distinct dimensions of a methodological approach as a whole.

(1) A methodological perspective is a way of approaching an object of study and is intended to point to or focus on a certain aspect of the object and capture or explain that aspect in terms of the characteristics of that aspect, together with the minimal metaphysical commitment that there is that aspect of the object. There are two important distinctions concerning methodological perspectives. First, there is the distinction between eligible and ineligible methodological perspectives. An eligible methodological perspective points to and captures a certain aspect that is really possessed by the object, while an ineligible one does otherwise. Second, there is the distinction between a methodological-perspective simplex and a methodological-perspective complex. A simplex is a single discernible methodological perspective, and a complex is either a combination of simplexes ('multiple-perspective complex'), or an association of one perspective (simplex) with a certain methodological guiding principle ('guiding-principle-associated perspective complex'). By 'perspective' below I mean a methodological perspective simplex, unless otherwise indicated.

(2) A methodological instrument is a way in which to implement, or give tools to realize a certain methodological perspective. Methodological instruments are largely neutral in the sense that they can serve to implement different methodological perspectives, though there is still the distinction between more and less effective methodological instruments in regard to a given methodological perspective.

See Bo Mou, "An Analysis of the Structure of Philosophical Methodology: In View of Comparative Philosophy". 
(3) A methodological guiding principle regulates and guides a certain methodological perspective (or perspectives) in regard to the object of study. Presupposed by the agent, it implicitly guides and regulates how the perspective should be evaluated and used and contributes to the establishment of its desiderata (especially, the purpose and focus that it is to serve). There are adequate and inadequate methodological guiding principles. For the sake of illustration, let me highlight one primary adequate guiding principle: in looking at the relation between the agent's current perspective in treating an object of study and other eligible perspectives (if any), a methodological guiding principle is considered adequate (in regard to recognizing perspective eligibility) when it allows in other eligible perspectives to complement the application of the current perspective and thus has the agent realize that these eligible perspectives do separately capture distinct aspects of the object and thus can jointly make complementary contributions to capturing the way the object is. It is considered inadequate if otherwise. This adequacy condition may be called the 'the perspectiveeligibility-recognizing condition'. More will be said on this condition.

On the one hand, the merit, status, and function of a methodological perspective per se can be evaluated independently of certain methodological guiding principles that the agent might presuppose in her actual application of the perspective, and taking a certain methodological perspective as a working perspective (this reflective practice per se) implies neither that one loses sight of other genuine aspects of the object, nor that one ignores or rejects other eligible perspectives in one's background thinking. On the other hand, it does matter whether one's taking a certain methodological perspective is regulated by an adequate or inadequate guiding principle, especially for the sake of constructive engagement of seemingly competing approaches, for an inadequate guiding principle will rule out certain eligible perspectives.

The following "method house" metaphor illustrates the relevant points. Suppose that a person intends to approach her destination, say, a house (the object of study), which has several entrances - say, a front door, side door, and upper story window (various aspects of the object of study) - and several paths, each of which is difficult to discern. If a path really leads to an entrance of the house, the path is called an eligible one. She chooses a path (methodological perspective) to approach the house, believing that the path leads to an entrance (say, the front door). In order to proceed on the difficult-to-discern path, she wields a certain tool (a methodological instrument) to clear her path - say, a machete if the path is overgrown with brambles, or a snow shovel if the path is heavily covered with snow. She also has a certain idea in her mind (methodological guiding principle) that explains why she takes that path, instead of another, and guides her to the house. Such a guiding idea can be adequate or inadequate. For example, if the guiding idea allows her to recognize that other eligible paths are compatible with her current path (that is, they all lead to the house), then her guiding idea is adequate; in contrast, if she fails to recognize this and thus understands her current path as exclusively eligible (the only path leading to the house), then her guiding idea is inadequate - even though her current path is, itself, eligible.

\section{Adequacy conditions}

To address the issue of how to look at the relationship of distinct methodological approaches (especially in terms of methodological perspectives) un- 
derlying distinct substantial approaches and to jointly-concerned issues with adequate methodological guiding principles, in this section I explain how it is possible to have adequate methodological guiding principles in cross-tradition philosophical inquiries by suggesting a set of adequacy conditions, which I also treat as a stepping stone and target of criticism for readers' participating in the engaging discussion in this connection.

Given that the term 'methodological approach' means a way responding to how to approach an object of study, the term is a generic term that can indicate a number of methodological ways. As explained above, in the context of philosophical inquiries, generally speaking, the notion of methodological approach can and needs to be refined into three distinct but related methodological notions for the sake of adequately characterizing three distinct methodological, but somehow related, methodological ways in philosophical inquiries, i.e., those of methodological perspective (or the perspective method), methodological instrument (or the instrumental method), and methodological guiding principle (or the guiding-principle method). As indicated earlier, for the purpose of cross-tradition understanding and constructive engagement, it is especially philosophically interesting, relevant, or even crucial to have an adequate methodological guiding principle, which the agent is expected to hold in evaluating the status and nature of the eligible methodological perspectives, applying her own methodological perspective, and looking at the relationship between her current working perspective and other methodological perspectives. As follows, to explore how it is possible to have adequate methodological guiding principles in doing philosophy comparatively, I suggest a set of ten conditions for adequate methodological guiding principles ('adequacy conditions' in short). This set of adequacy conditions is not necessarily exhaustive or exclusive, and it is not intended as dogma. The conditions are open to criticism for their validity and explanatory force. To help the reader understand the points of these adequacy conditions, I will use some examples in comparative studies in philosophy for their illustrations.

(1) The same-object-recognizing condition (against the "anything goes" orientation). A methodological guiding principle is considered adequate (in this connection) if, given an object of study, it enables the agent to recognize that there is a way that the object objectively is such that it is not the case that "anything goes", and we can all talk about that same object even though we may say different things (concerning distinct aspects of the object) about it. In contrast, it is considered inadequate (in this connection) if otherwise. This adequacy condition may be called a 'minimal' truth-pursuing condition in the sense that it is presupposed by the remaining kinds of adequacy conditions for the sake of capturing the way the object is (or is to be) if the truth pursuit is one strategic goal. ${ }^{3}$ [The identity of a (genuine) object of study in philosophy is understood broadly: an object of study can be a naturally produced object in physical reality, a socially constructed object in social reality, an abstract object out of theoretic construction, a 'linguistic' object which is introduced linguisti-

3

As for the issue of truth-pursuit as one strategic goal in philosophy (or labeled 'the truthpursuit norm in philosophy'), there is much literature on this important and challenging issue, which I cannot explore here with consideration of the purpose of this writing, but resort to readers' pre-theoretic understanding of truth. 
cally, a thinker's text, or an object of philosophical inquiry on an issue, topic or theme.]

For example, consider our comparative examination of Confucius' and Socrates' methodological perspectives in dialogue on the issue of (filial) piety. ${ }^{4}$ One might raise a good question: "When we are conducting comparative philosophy, how can we know that different thinkers from different traditions are talking about the same object? In other words, the same 'house' in my metaphor?" When we carry out this comparative examination of Socrates' and Confucius' distinct approaches to how to understand '(filial) piety', the addressed general 'same-object' issue shows up here as follows: "Were both thinkers talking about the same "piety'?" Well, both people in the West and people in the East have parents (instead of the guys in one location being produced from nowhere and thus having no parents), and both can know they are talking about the same issue of filial piety and the same (type of) object (a kind of respect feeling) that both groups of guys are really experiencing in their real lives towards their parents (if they do have parents). By looking at the Euthyphro and Confucius' 2.5-2.8 of the Analects, both talk about what constitute the sons'/daughters' "reverence" feeling, emotion, and attitude towards their parents; in this way, though this emotion/attitudes is labeled 'filial piety' in English and '孝' in Chinese, clearly they are talking about the same object in human society on this same earth.

(2) The perspective-eligibility-recognizing condition. A methodological guiding principle that is held or presupposed by the agent who uses some eligible methodological perspective concerning an object of study as her current working perspective is considered adequate (in this connection) when this guiding principle renders other eligible methodological perspectives (if any) also eligible and somehow compatible with the application of the current working perspective. In contrast, it is considered inadequate (in this connection) if otherwise. This adequacy condition may be called a 'minimal' multiple-perspectives-treating condition in the sense that it is presupposed by the remaining kinds of adequacy conditions concerning how to look at the relationship between distinct perspectives.

For example, again consider the two samples of methodological perspectives, namely, the Socrates-style being-aspect-concerned perspective and the Confucius-style becoming-aspect-concerned perspective. The two kinds of methodological perspectives point respectively to the two most basic modes of existence (being and becoming) of things in the world that are typically possessed simultaneously by most things in nature. Now the object of study under Socrates' and Confucius' examination is (filial) piety. If piety as the object of study genuinely possesses both its being and becoming aspects, Socrates' and Confucius' are both eligible in regard to our reflective examination of piety. In this way, a methodological guiding principle that renders both methodological perspectives eligible on the issue of piety would have the perspective-eligibility-recognizing adequacy.

(3) The agent-purpose-sensitivity condition. A methodological guiding principle is considered adequate (in this connection) if it enables the agent to have her choice of a certain working perspective, among eligible metho- 
dological perspectives concerning an object of study, sensitive to the agent's purpose and thus renders the most applicable or the most appropriate (the best relative to that purpose) the perspective that (best) serves that purpose. In contrast, it is considered inadequate (in this connection) if otherwise.

For example, again consider the two sample methodological perspectives, the Socrates-style being-aspect-concerned perspective and the Confuciusstyle becoming-aspect-concerned perspective. Given that the two methodological perspectives are both eligible in regard to the issue of piety, a methodological guiding principle that sets out to decide which methodological perspective among the two is to be taken by an agent herself as her working perspective, or how to evaluate the validity of some other agent's working perspective (either one) should be sensitive to the agent's purpose or her own focus on which aspect of piety is to be captured in a certain context. The methodological guiding principle then has agentpurpose-sensitivity adequacy.

(4) The equality-status-granting condition. A methodological guiding principle is considered adequate (in this connection) if it renders all the eligible methodological perspectives (perspective simplexes) concerning an object of study equal in the following two senses: being equally necessary for the sake of a complete account of the object and being equally local from the global point of view that transcends any local and finite methodological perspectives, although one eligible perspective can be rendered more (or even the most) suitable than others only relative to its associated purpose and the aspect of the object to which it points;

Socrates's distinctive methodological approach which he consciously and systematically pursues in some earlier Platonic dialogues is called elenkhos in Greek, more usually written elenchus, literally meaning 'refutation'. The elenchus approach can be seen most clearly in such short dialogues as Laches (to define bravery) and Euthyphro (to define piety), but it is also used in Book I of the Republic, the first part of Meno, Protagoras, and Gorgias. The presentation of such a methodological approach in the Euthyphro is usually considered the neatest, most concise, and representative, especially in connection with its perspective and instrumental dimensions. The manifest level or layer of the elenchus approach clearly reveals itself through the dialogue between Socrates and Euthyphro on the latter's four definitions of piety presented in the Euthyphro (focusing on $5 \mathrm{a}-15 \mathrm{~d}$, especially see $5 \mathrm{c}-\mathrm{d})$; Socrates puts forward the question "What is piety?" and sets up three conditions or requirements to be met: (1) some feature that is the same in every pious action; (2) this feature will not be shared by any impious action; (3) it will be that feature (or the lack of it) that makes an action pious (or impious). The elenchus methodological approach can be applied to anything that deserves reflective examination. For good examinations of Socrates' elenchus method, see Gregory Vlastos, "The
Socratic Elenchus", in: Julia Annas (ed.), $O x$ ford Studies in Ancient Philosophy, Vol. 1, Clarendon Press, Oxford 1983, pp. 27-58; Donald Davidson, "Dialectic and Dialogue" (1994), reprinted in: Donald Davidson, Truth, Language, and History, Clarendon Press, Oxford 2005, pp. 251-259, doi: https://doi.org/ 10.1093/019823757x.003.0017. In contrast, Confucius's becoming-concerned perspective in his methodological approach to characterizing those things like xiao (孝 filial piety) and ren (仁 tentatively glossed as 'humanity') is revealed in the Analects. Indeed, interestingly enough, like Socrates, Confucius also had dialogue with his interlocutors on what (filial) piety is (especially see sections 2.5, 2.6, 2.7 and 2.8 in the Analects). Confucius exhibits no tendency to question important words in his moral vocabulary by giving Socrates-style universal definitions or meaning formulae. Instead, he gives different answers to different interlocutors depending on who asked the questions, the degree of his or her preliminary understanding of filial piety, in what context the question was raised, etc. His answers are designed to give the disciplequestioner some useful guidance. Although it is unclear exactly why the cited sections 2.5-2.8 were arranged in the order they were, it turns out that Confucius's four answers to the same question went further and further. 
thus none of them is absolutely superior (or inferior) to the others in the above senses. In contrast, it is considered inadequate (in this connection) if otherwise.

For example, again consider the two sample methodological perspectives, the Socrates-style being-aspect-concerned perspective and the Confuciusstyle becoming-aspect-concerned perspective and assume that both are eligible methodological perspectives that point respectively to the being aspect and becoming aspect both of which are really possessed by piety. When one resorts to a certain methodological guiding principle to guide one's evaluation of the status of the Socrates-style being-aspect-concerned perspective (or the Confucius-style becoming-aspect-concerned perspective) and thus renders it indiscriminately and absolutely superior to the Confucius-style becoming-aspect-concerned perspective (or the Socrates-style being-aspect-concerned perspective), the methodological guiding principle thus fails to have the equality-status-granting adequacy concerning the aforementioned two methodological perspectives on the issue of piety. In contrast, if a methodological guiding principle renders one of the two better than the other, or most suitable only in view of a certain context and in regard to a certain aspect of piety to which the perspective in question points but without viewing it absolutely superior to the other, this methodological guiding principle will thus meet the equality-status-granting condition concerning the aforementioned two methodological perspectives on the issue of piety.

(5) The new-eligible-perspective-possibility-recognizing condition. A methodological guiding principle is considered adequate (in this connection) if it enables the agent to have an open-minded attitude toward the possibility of a new eligible perspective concerning an object of study that is to point to some genuine aspect of the object but has yet to be realized by the agent because of the 'unknown identity' status of that aspect. A methodological guiding principle is considered inadequate (in this connection) if otherwise.

For example, again consider the two sample methodological perspectives, the Socrates-style being-aspect-concerned perspective and the Confuciusstyle becoming-aspect-concerned perspective and assume that both are eligible methodological perspectives on the issue of piety. If, besides the two methodological perspectives, a methodological guiding principle has its open-minded attitude towards the possibility of new (yet-to-be-recognized) aspects, dimensions or layers of piety, and thus the possibility of new eligible methodological perspectives that are to point to and explain them, the guiding principle thus enjoys the new-eligible-perspective-possibility-recognizing adequacy. In contrast, any methodological guiding principle that renders exclusive and exhaustive the current working perspective (or the current stock of methodological perspectives that are so far epistemologically available), the guiding principle is thus inadequate because it fails to meet the condition of the new-eligible-perspective-possibility-recognizing adequacy.

(6) The dynamic-development-sensitivity condition. A methodological guiding principle is considered adequate (in this connection) if it guides the agent to be sensitive to the dynamic development (if any) of an object of study for the sake of realizing and understanding which aspects are still 
genuinely possessed by the object (thus, which methodological perspectives are still eligible) and which ones not (thus, which perspectives are no longer eligible). In contrast, it is considered inadequate in this connection if otherwise. This adequacy condition calls the agent's attention and sensitivity to this: during the process of dynamic development (if any) of an object of study, the object might develop some new aspect(s) while losing some of its previous aspect(s); consequently, the methodological perspective with regard to the previous aspect of the object might not be absolutely or permanently eligible, and a previously ineligible perspective might become eligible because of its pointing to the new aspect. This adequacy condition highlights the need for the agent's sensitivity to the dynamic development (if any) of the object of study, one important front which can be easily ignored by an agent who is guided by an inadequate methodological guiding principle in this connection.

For example, consider an imaginary case of a couple's personal relationship. Suppose that at its earlier stage the couple's relation was good and harmonious, which rendered a yin-yang perspective "eligible" in describing their relationship and thus "eligible" in taking care of the "legal" dimension of their relationship: the couple then decided they (should) stay together with regard to their legal relationship. However, suppose that later on their relationship turned bad with serious conflict; the conflict is so severe that the "harmony" aspect of their legal relationship is not there anymore; in this situation, the yin-yang perspective to look at the current situation is not "eligible" anymore, while the Hegelian model as one perspective to treat the current case has become "eligible", though it was "ineligible" to capture the earlier stage of their relationship.

(7) The complementarity-seeking condition. Given that multiple, seemingly competing eligible methodological perspectives concerning an object of study, whose identity can result from dynamic development if any, turn out to be complementary (in the sense that they point to and capture distinct aspects or layers of the object, which jointly contribute to the identity of the object in a mutually-supportive and supplementary way, and thus are indispensable for a complete understanding of the object), a methodological guiding principle is considered adequate (in this connection) if it captures the complementary character of the involved aspects of the object and thus seeks complementary connection and harmonious balance between those perspectives for the sake of capturing the way the object is in this connection. In contrast, it is considered inadequate (in this connection) if otherwise.

For example, again, consider the two sample methodological perspectives; the Socrates-style being-aspect-concerned perspective and the Confucius-style becoming-aspect-concerned perspective. The two kinds of methodological perspectives point respectively to the two most basic modes of existence, being and becoming, of things in the world that are typically possessed simultaneously by most things in nature. Now the object of study under Socrates' and Confucius' examination is (filial) piety. Suppose that piety as the object of study genuinely possesses both its being and becoming aspects and that both aspects are interdependent, interpenetrating, interactive and complementary in regard to the constitution of piety. Then the Socrates-style being-aspect-concerned perspective and the Confucius-style becoming-aspect-concerned perspective are complementary instead of being incompatible or opposed to each other on 
the issue of piety. In this way, any methodological guiding principle that renders the two methodological perspectives complementary and seeks their complementary connection and joint contribution to a complete understanding of the issue of piety thus meets the complementarity-seeking condition. If otherwise, a methodological guiding principle would be inadequate in this connection on the issue. The complementarity-seeking condition essentially reflects the point of the yin-yang model of interaction and transformation.

(8) The sublation-seeking condition concerning guiding-principle-associated perspective complexes with complementary perspective simplexes. Given that there are two seemingly competing guiding-principle-associated perspective complexes concerning an object of study whose perspective parts are eligible (i.e., capturing distinct aspects of the object) but whose respectively associated methodological guiding principles are genuinely competing or incompatible (either because one of them is inadequate or because both are inadequate in other connections addressed above), such a methodological guiding principle would be considered adequate (in this connection) if it seeks a due solution through a Hegelian synthetic balance via sublation that keeps what are reasonable or appropriate from both guiding-principle-associated perspective complexes (i.e., their eligible perspectives, maybe plus some adequate guiding principle from one perspective complex if any) while disregarding what are not, i.e., the inadequate guiding principle (or principles) in one (or both) of the perspective complexes. In contrast, it is considered inadequate (in this connection) if otherwise.

For example, there might be two seemingly competing guiding-principle-associated perspective complexes as two approaches to build up a social-economic community: the profit-seeking-only perspective complex (i.e., the profit-seeking perspective that is associated with a guiding principle which renders the perspective exclusively eligible) and the welfare-seeking-only perspective (i.e., the welfare-seeking perspective that is associated with a guiding principle which renders the perspective exclusively eligible). It might be the case that a social-economic community does or should have both its profit-seeking layer and its welfare-seeking layer for the sake of its well-being. In this case, what really makes the two perspective complexes competing or incompatible would be their respectively associated guiding principles that render their respectively guided perspectives exclusively eligible. Then, when a methodological guiding principle seeks a synthetic balance (via sublation) to bring about a new approach that keeps what is reasonable in the two perspective complexes (i.e., the two involved perspective simplexes per se) while disregarding what is not (i.e., the two involved inadequate guiding principles), the methodological guiding principle would be considered to be adequate because it meets the sublation-seeking condition in this case.

(9) The genuine-contradiction (if any)-recognizing-while-constructive-equilibrium-seeking condition (concerning genuinely competing perspectives). Given that different seemingly competing but eligible methodological perspectives concerning an object of study, whose identity can result from dynamic development if any, turn out to be genuinely "contradictory" (in the sense that they point to and capture distinct aspects or layers of the object, which jointly contribute to the identity of the object 
but also jointly capture some internal contradiction really possessed by the object, and thus are indispensable for a complete understanding of the object), a methodological guiding principle is considered adequate (in this connection) if it captures the genuine-contradiction state of the involved aspects of the object and seeks for a certain constructive equilibrium between those perspectives for the sake of capturing the way the object is in this connection. In contrast, it is considered inadequate (in this connection) if otherwise. Given that some internal contradiction really exists in the object and substantially contributes to the identity of the object, this adequacy condition consists of these: $<1>$ recognizing that some genuine contradiction is possessed by the object and brings about a certain internal tension of the object $;^{5}<2>$ thus recognizing that each of the involved perspectives that does point to and capture one of the "contradiction" aspects of the object is eligible and contributes to our understanding and treatment of the "contradictory" dimension of the object; $<3>$ seeking constructive equilibrium of the involved perspectives. The foregoing sub-condition $<3>$ is to be implemented in distinct ways, being sensitive to the nature of different types of objects of study. Let me consider some sample cases for illustration. For an object of study as part of social reality whose constitution is based on or related to a certain human convention or artifact, seeking constructive equilibrium of the involved perspectives might mean seeking a solution (or a way towards a solution) that would bring about a kind of dynamic development of the object [see the foregoing adequacy condition (6)] and change the original "contradictory" aspects to complementary aspects of the newly-developed identity of the object [see the foregoing adequacy condition (7)]. In contrast, for an object of study as part of physical natural reality whose constitution is naturally determined in nature, independently of human subjective intentions, seeking constructive equilibrium of the involved perspectives might mean doing justice to those involved perspectives that points to and capture distinct "contradictory" aspects of the object (such as those involved in the object's internal changing process and external moving process) and delivering them in a consistent way for the sake of consistency and effective communication: for this purpose, one constructive-balance point is to distinguish various forms of the principle of non-contradiction and maintain the principle of non-contradiction concerning linguistic expressions of distinct perspectives that respectively capture the "contradictory" aspects of the object. ${ }^{6}$

5

It should be noted that this does not go against but actually maintains the truth-pursuit norm. Truth-pursuit is to reflectively pursue capturing the way things are (are to be). If there is a genuine contradiction, then recognizing this genuine contradiction (or the "contradictory" dimension of an object) is actually implementing the norm, rather than violating it. The truth-pursuit norm does not automatically or necessarily mean that there is one single static entity waiting there for one's discovery Indeed, the truth-pursuit norm includes the reflective pursuit of capturing the way things are to be, especially for some social issues as objects of study. I do not examine this connection of the philosophical issue of truth in my current writing, with consideration of the purpose here, but explore it in another article.

For a recent engaging discussion of the principle of non-contradiction, see Graham Priest, JC Beall, Bradley Armour-Garb (eds.), The Law of Non-Contradiction: New Philosophical Essays, Oxford University Press, Oxford 2006, doi: https://doi.org/10.1093/acprof: oso/9780199265176.001.0001. 
(10) The open-mind-oriented self-criticism condition. This condition is listed last but not least; though the foregoing conditions, especially (5) and (9) implicitly point to this condition, it is reflectively worth specifying and highlighting separately, as this condition would fundamentally distinguish a genuinely philosophical attitude towards distinct critical views from an absolutely faith-oriented attitude that takes its foundation thing for granted and would not allow for any criticism and challenges. The point of this condition is not that one cannot firmly maintain one's foundation thing or some axiom-like basic principle - it is clear that one has to stop somewhere in one's account or theoretic system; rather, the point of this condition is this: one needs to always maintain an open-mind reflective attitude towards all critical challenges to the basic principle(s) on which one's account or theoretic system is based and is ready to modify, revise, or even give up the basic principle if it turns out to be wrong or mistaken through reasonable justification. In this way, any methodological guiding principle that possesses such an open-minded self-critical character and thus meets the condition would be adequate in this connection. If otherwise, a methodological guiding principle would be inadequate in this connection.

There are several due notes on the foregoing ten "adequacy" conditions for maintaining an adequate methodological guiding principle. First, condition (1), given an object of study, is presupposed by the remaining kind of adequacy conditions as the truth pursuit (capturing the way the object is) is taken as one strategic goal against radical "anything goes" relativism. Second, condition (2) is presupposed by the subsequent kinds of conditions (3) through (9). Third, if the relation between eligible methodological perspectives under consideration is really complementary, then one needs to resort to condition (7); if they appear not to be complementary, then we really need to have further examination of whether any of these perspectives are perspective simplex or perspective complex (i.e., actually it is a combination of one perspective simplex plus a methodological guiding principle - 'guiding-principle-associated perspective complex' as indicted above when I characterize what a methodological perspective is); if it is the latter, one needs to resort to condition (8); if it is the former, one needs to resort to condition (9). Fourth, however, to thoroughly fulfill conditions (1) and (2), condition (6) needs to be met if the object has its dynamic-development dimension. Fifth, last but not least, in the same philosophical spirit as is indicated in the foregoing adequacy condition (10), this "adequacy-condition" list per se is open to criticism, instead of being dogmatically maintained. Indeed, this set of adequacy conditions is suggested here to serve two purposes: for one thing, it is to explain how it is possible to have adequate methodological guiding principles in cross-tradition philosophical inquiries; for another thing, it is to provide readers with an engaging starting point or an effective stepping stone, which per se is not intended to be dogmatically imposed on readers, but expected to be a target of critical examination in their own engaging exploration of the issue. 


\title{
Kako je moguć konstruktivni angažman u komparativnom filozofiranju
}

\begin{abstract}
Sažetak
U ovome članku, na temelju određenih ranijih relevantnih radova o ovoj problematici, namjeravam dodatno istražiti niz uvjeta za održavanje adekvatnih vodećih metodoloških principa koji se bave pitanjem kako promatrati odnos između metodoloških perspektiva u komparativno angažiranom istraživanju u filozofiji. Svrha je ovog teksta istražiti kako, u globalnom kontekstu, različiti pristupi u filozofiji mogu biti angažirani tako da stupe u konstruktivan dijalog i da doprinesu razvoju filozofije i društva.
\end{abstract}

\section{Ključne riječi}

konstruktivni angažman, komparativna filozofija, vodeći metodološki principi (njihovi uvjeti adekvacije), metodološke perspektive

\section{Bo Mou}

\section{Wie ein konstruktives Engagement im komparativen Philosophieren möglich ist}

\begin{abstract}
Zusammenfassung
In diesem Artikel beabsichtige ich, auf der Grundlage einiger früherer einschlägiger Arbeiten zu diesem Thema, eine Reihe von Bedingungen für die Aufrechterhaltung adäquater methodologischer Leitprinzipien weiter zu untersuchen, die sich mit der Frage befassen, wie das Verhältnis zwischen verschiedenen methodologischen Perspektiven in der komparativ engagierten Forschung in der Philosophie einzuschätzen ist. Die Absicht dieses Aufsatzes ist es, zu erforschen, wie - im globalen Kontext - unterschiedliche Ansätze in der Philosophie engagiert werden können, um konstruktiv miteinander zu kommunizieren und einen gemeinsamen Beitrag zur Entwicklung von Philosophie und Gesellschaft zu leisten.
\end{abstract}

\section{Schlüsselwörter}

konstruktives Engagement, komparative Philosophie, methodologische Leitprinzipien (und deren Adäquatheitsbedingungen), methodologische Perspektiven

\section{Bo Mou}

\section{Comment un engagement constructif est-il possible dans l'activité philosophique comparée}

\section{Résumé}

J'ai l'intention dans cet article, sur la base de travaux antérieurs et pertinents pour la problématique, d'examiner une suite de conditions visant à maintenir les principes méthodologiques directeurs et adéquats qui s'intéressent à la question comment les diverses perspectives méthodologiques interagissent au sein de leur engagement en philosophie comparée. Le but de ce texte est d'explorer, dans un contexte globale, la manière dont ces approches peuvent s'engager dans un dialogue constructif qui contribue au développement de la philosophie et de la société.

\section{Mots-clés}

engagement constructif, philosophie comparée, principes méthodologiques directeurs (leurs conditions d'adéquation), perspectives méthodologiques 